\title{
Image-Guided Stereotactic Ventricular Catheter Placement for Refractory Idiopathic Intracranial Hypertension: Accuracy and Effectiveness
}

\author{
ESAM A. MOKBEL, M.D. and ESAM MOUNIR, M.D. \\ The Department of Neurosurgery, Faculty of Medicine, Tanta University
}

\begin{abstract}
Background: Although lumboperitoneal shunt (LPS) is a common procedure for surgical management of idiopathic intracranial hypertension (IIH). However, many studies documented a high failure and complications rate. Ventricular shunts were not commonly used for surgical management IIH due to the difficulty of inserting a shunt into normal or slit ventricles. Also, stereotactic surgery not available in every hospital.
\end{abstract}

Aim of the Study: This article retrospectively evaluate the accuracy, efficacy, and safety of using stereotactic imageguided insertion of ventricular catheter in patients with IIH.

Patients and Methods: The authors reviewed the clinical records of all patients in whom stereotaxy was used to guide the placement of a ventricular catheter for IIH. Stereotactic guided ventricular catheter placements were performed on sixteen patients presenting with clinical manifestation of IHH to target the frontal horn of the lateral ventricle after failure of traditional medical or previous surgical treatment.

Results: We had fourteen females and two males. Their age ranged from 20 to 45 years (average 29.7). The mean follow-up period was 43.9 months (ranged from 10 to 84 months). Eleven patients had previous LPS insertion with at least one trial of revision. Five patients subjected to stereotactic VPS as a first procedure. Accurate ventricular catheter placement was done from the first trial in all patients which was confirmed on postoperative CT scan. Four patients underwent stereotactic ventriculo-atrial shunts due to decrease CSF absorptive capacity of peritoneal cavity due to multiple lumboperitoneal shunt revision. All patients showed improvement or stabilization of their visual manifestation after ventricular shunt insertion. Headache improved in fourteen patients whereas two patients still had headache that respond to medical treatment. We had no mortality and two patients required shunt revision.

Conclusions: Image-guided stereotactic ventricular catheter placement is an effective, safe and durable management option that can help in management of IIH when the ordinary medical and surgical methods fail. Also it may be the first choice in certain selected cases.

Key Words: Stereotactic - Ventricular - Refractory - Idiopathic - Intracranial.

Correspondence to: Dr. Esam A. Mokbel, The Department of Neurosurgery, Faculty of Medicine, Tanta University

\section{Introduction}

IDIOPATHIC intracranial hypertension (IIH), is a disorder caused by increased intracranial pressure (ICP) of unknown cause without any clinical, laboratory or radiological evidence of any intracranial pathology $[\mathbf{1}, \mathbf{2}, \mathbf{3}]$. This disorder may affect children and adults, but women are more frequently affected than men $[4,5]$. IIH is common in obese females in reproductive period [6-10].

IIH was previously called benign intracranial hypertension, or pseudotumor cerebri, but with the greater understanding of its associated vision loss, those terms were no longer appropriate. IIH is defined by the revised Modified Dandy Criteria, which include (1) Symptoms and signs of elevated ICP, (2) No focal signs except $6^{\text {th }}$ nerve palsy, (3) Cerebrospinal fluid (CSF) opening pressure at least $25 \mathrm{~cm} \mathrm{H}_{2} \mathrm{O}$ with normal CSF composition, and (4) Normal brain imaging that does not identify a cause for elevated ICP. Friedman and Jacobson, in 2002 provided updated diagnostic criteria of Modified Dandy Criteria for IIH for purposes of routine patient management. Additionally, clinical guidelines are included to help in differentiation IIH from other causes of increased ICP [3] (Table 1).

Table (1): Updated criteria for diagnosing idiopathic intracranial hypertension [3]

1- If symptoms and signs present, they may only reflect those of generalized intracranial hypertension or papilledema.

2- Reported increased intracranial tension measured in the lateral decubitus position.

3- Normal CSF composition.

4- No hydrocephalus, mass, structural, or vascular lesion on MRI or post-contrast CT for typical patients, and MRI and MR venography for others.

5- No other cause of increased ICP identified. 
The pathogenesis of IIH not known yet. Brain edema, increased cerebral blood volume, and increased CSF production were postulated as causes of IIH [11,12].

Headache is the most common presenting symptom and occurs in about $60 \%-90 \%$ of patients. It may be associated with nausea, transient visual blackout, double or blurring of vision. Pulsatile tinnitus is present in approximately $50 \%$ of patients. Nonspecific neurological symptoms as cervical and shoulder pain, and ataxia, may occurred [7,13-16].

All grades of papilledema may be found, from mild blurring of the optic disc margins to total disc swelling with exudates and hemorrhages, is the hallmark sign of IIH. The disc edema is usually bilateral, but it can be asymmetric or unilateral. Untreated papilledema can lead to progressive, irreversible loss of vision in about $30 \%$ of patients $[1,17]$.

Visual field deficits may occur at presentation in about $90 \%$ of cases. The most common defect is an enlarged blind spot $[\mathbf{1 3 , 1 8 , 1 9 ]}$.

There are several treatment modalities that appear to be effective. Medical treatment provides relief for many patients and is often the initial treatment of choice. Serial lumbar puncture is also beneficial because it reduces CSF pressure. However, it is not without risk; low-pressure headaches, infection, radiculopathy, and arachnoiditis have been documented. IIH has been associated with obesity, and many patients do improve with weight loss. Indications for surgical treatment of IIH include significant visual loss, progressive visual loss, or severe headache that persists despite adequate medical treatment [19-26].

Surgical interventions include optic nerve sheath fenestration (ONSF) and CSF shunting procedures. ONSF has been used when the main symptom is the acute visual deterioration. It can be done bilaterally in two stages. ONSF is effective at relieving papilledema and progressive visual loss [27-32].

In contrast to CSF diversionary procedures, however, ONSF is ineffective at relieving headaches. The complications of ONSF include peripapillary hemorrhage, new visual field deficits, blindness, cranial nerve paresis, and stroke [33-36]. The most frequently performed CSF diversion procedure for surgical management of IIH is lumboperitoneal shunt (LPS) placement [38-41]. LPS results in rapid resolution of symptoms of elevated ICP. Although it is quite effective, shunt failure and low pressure-induced headaches are frequently seen. The difficulty of introducing a catheter into ventricles of normal or small size has led most surgeons to favor LPS over ventriculoperitoneal shunt (VPS) in these patients. Stereotaxy, however, may be used to overcome this limitation of traditional VPS placement $[\mathbf{4 2 , 4 3 ]}$.

The present study retrospectively evaluate the accuracy, efficacy, and safety of using stereotactic image-guided insertion of ventricular catheter in patients with IIH as an alternative to lumboperitoneal shunting.

\section{Patients and Methods}

Sixteen patients had IIH based on the updated criteria for IIH (Table 1) were managed by stereotactic CT-guided ventricular catheter placement at Tanta University Hospital from January 2008 to Feb. 2015. All participating patients gave informed consent.

Preoperatively, all patients subjected to complete ophthalmological and neurological examination.

\section{The indications for surgery were:}

Failure of LPS (CSF leak and wound dehiscence in 5 cases, sciatica from radicular compression in 2 case and defective absorptive capacity of peritoneal cavity following repeated LPS in 4 patients) in 11 patients. The later 4 patients subjected to VA shunt (Table 3).

The procedure was used as the treatment from the beginning after failure of conservative medical treatment and repeated lumbar punctures in five patients. IIH patients who failed maximal medical therapy and have intractable headaches or have progressive or acute visual deterioration have been considered as candidates for surgical intervention [44].

Patients' data and clinical symptoms \& signs are listed in Table (2).

\section{Surgical technique:}

A CT-guided frame-based stereotactic ventricular catheter placement technique was used in all patients. Under local anesthesia while patient on sitting position, we fix the stereotactic frame (Cosman-Robert-wells (CRW) or Zamorano-Dujovny (ZD) to patient's head. Stereotactic CT scan of the head were obtained. A multiplanar reconstruction software, Praezis plus 3 was used for registration and target point selection which was chosen in the 
frontal horn anterior to the foramen of Monro in all patients. Under local anesthesia and in the semisetting position, a right parieto-occipital burr hole was performed according to the surgical planning (approximately $6 \mathrm{~cm}$ superior to the external occipital protuberance and $3 \mathrm{~cm}$ from midline). A ventricular catheter was stereotactically introduced through the ventricle up to the frontal horn anterior to the foramen of Monro and then fixed to the valve's reservoir which was then fixed to the peri- osteum in the ordinary way. We temporarily close the wound, and the stereotactic frame was removed. Finally, the distal catheter was inserted inside the peritoneal cavity in 12 patients using standard neurosurgical procedure. Because of defective CSF absorption by the peritoneal cavity in four patients, the distal catheter was inserted percutaneously into the right atrium. We used CSF flow control valve, Burr hole $16 \mathrm{~mm}$ medium pressure, Medtronic, Minneapolis, USA.

Table (2): Shows of patients' data, clinical symptoms \& signs, and results.

\begin{tabular}{|c|c|c|c|c|c|c|c|c|c|}
\hline \multirow{2}{*}{$\begin{array}{l}\text { Case } \\
\text { No. }\end{array}$} & \multirow{2}{*}{$\begin{array}{l}\text { Age/y } \\
\text { Sex }\end{array}$} & \multicolumn{2}{|c|}{ Preoperative } & \multirow{2}{*}{$\begin{array}{l}\text { Prior } \\
\text { revision }\end{array}$} & \multirow{2}{*}{ Surgery } & \multicolumn{2}{|c|}{ Postoperative } & \multirow{2}{*}{$\begin{array}{l}\text { Shunt } \\
\text { revision }\end{array}$} & \multirow{2}{*}{ Follow-up } \\
\hline & & HA & Ophth. find & & & HA & Ophth. find & & \\
\hline 1 & $22 \mathrm{~F}$ & Yes & VFD & LPS (3) & VAS & Inter & Improved & No & 84 mos. \\
\hline 2 & $24 \mathrm{~F}$ & Yes & P \& VFD & No & VPS & No & Improved & No & 74 mos. \\
\hline 3 & $20 \mathrm{M}$ & Yes & $\mathrm{P}$ & No & VPS & No & Improved & No & 68 mos. \\
\hline 4 & $36 \mathrm{~F}$ & Yes & $\mathrm{P}$ & LPS (2) & VAS & Inter & Improved & No & 64 mos. \\
\hline 5 & $26 \mathrm{~F}$ & Yes & $\mathrm{P}$ & LPS (1) & VPS & No & Improved & Yes & 60 mos. \\
\hline 6 & $27 \mathrm{~F}$ & Yes & P \& VFD & No & VPS & No & Improved & No & 55 mos. \\
\hline 7 & $40 \mathrm{~F}$ & Yes & P \& VFD & LPS (2) & VPS & No & Improved & No & 54 mos. \\
\hline 8 & $23 \mathrm{~F}$ & Yes & P \& VFD & LPS (2) & VAS & No & Improved & No & 48 mos. \\
\hline 9 & $25 \mathrm{~F}$ & Yes & P \& VFD & LPS (1) & VPS & Inter & Improved & No & 45 mos. \\
\hline 10 & $30 \mathrm{~F}$ & Yes & $\mathrm{P}$ & LPS (2) & VPS & No & Improved & Yes & 35 mos. \\
\hline 11 & $34 \mathrm{~F}$ & Yes & P \& VFD & No & VPS & No & Improved & No & 30 mos. \\
\hline 12 & $38 \mathrm{~F}$ & Yes & $\mathrm{P}$ & LPS (2) & VPS & Inter & Improved & No & 24 mos. \\
\hline 13 & $45 \mathrm{~F}$ & Yes & P \& VFD & LPS (3) & VAS & No & Improved & No & 20 mos. \\
\hline 14 & $24 \mathrm{M}$ & Yes & $\mathrm{P}$ & No & VPS & No & Improved & No & 17 mos. \\
\hline 15 & $28 \mathrm{~F}$ & Yes & VFD & LPS (1) & VPS & No & Improved & No & 15 mos. \\
\hline 16 & $33 \mathrm{~F}$ & Yes & P \& VFD & LPS (2) & VPS & Inter & Improved & No & 10 mos. \\
\hline
\end{tabular}
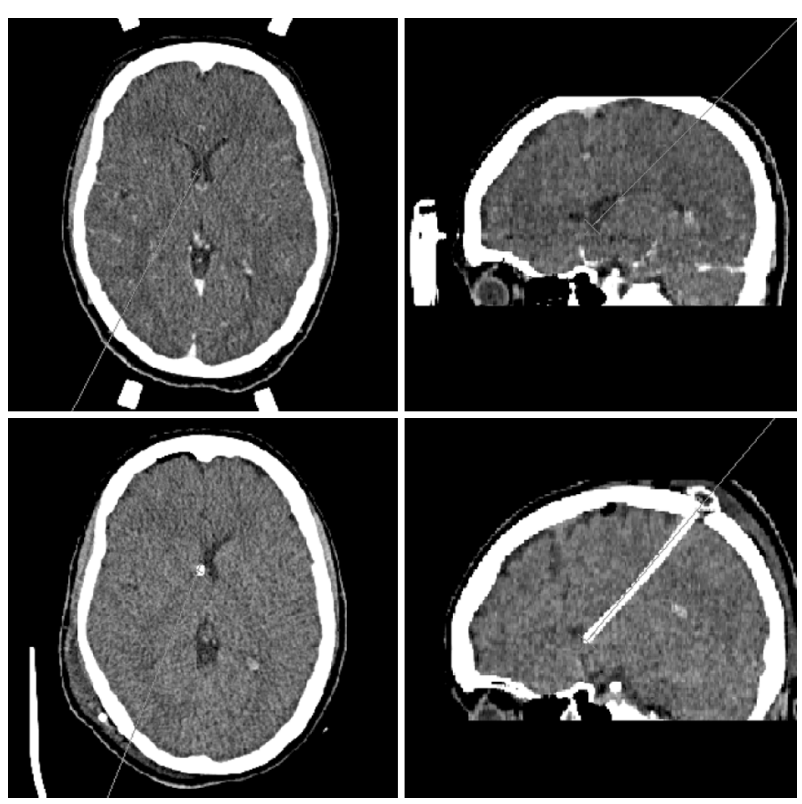

Fig. (1): Upper: Operative CT showing target point at frontal horn anterior to foramen of Monro, Lower: Postoperative $\mathrm{CT}$ axial and sagittal views showing accurate placement of ventricular catheter.

\section{Results}

This study included sixteen patients (fourteen women and two men) underwent stereotactic CTguided ventricular catheter insertion. Their ages ranged from 20 to 45 years with mean age of 29.7 years. The mean follow-up period was 43.9 months (ranged from 10 to 84 months).

Eleven patients had undergone previous LPS.

Table (3): Shows causes of LPS failure.

\begin{tabular}{lcc}
\hline $\begin{array}{l}\text { Cause of LPS } \\
\text { failure }\end{array}$ & No. of cases & $\begin{array}{c}\text { Surgical } \\
\text { procedure }\end{array}$ \\
\hline CSF leak \& wound infection & 5 & VPS \\
Sciatica & 2 & VPS \\
$\begin{array}{l}\text { Decrease absorptive } \\
\text { capacity of peritoneal cavity }\end{array}$ & 4 & VAS \\
\hline
\end{tabular}

All the patients had severe headache not relieved by medical management and had visual symptoms and signs consisting of visual obscurations, visual field deficit, or papilledema. 
Accurate ventricular catheter placement was done from the first trial in all patients. All patients experienced improvement of their visual symptoms after ventricular shunt insertion or remain stable. Headache improved in fourteen patients whereas two patients still had infrequent attacks of headache that respond to medical treatment.

We had five patients subjected to stereotactic VPS as a first procedure after a trial of medical treatment and repeated lumbar punctures had failed. They didn't develop shunt failure.

We have reported a female patient aged 27 years (case 6), presented with spontaneous CSF rhinorrhea after she has stopped the medical treatment. Preoperative MRI revealed Chiari I malformation with marked tonsillar herniation together with empty sella (Fig. 2). We decided to operate upon her with stereotactic ventricular catheter placement as a first choice. This patient improved clinically and the CSF rhinorrhea stopped spontaneously 3 weeks after surgery. This patient was clinically stable during follow-up (55 months). Two patient required revision of the VP shunt for distal obstruction. No mortality or significant morbidity were reported. Any case of intracranial hemorrhages, shunt infection, over drainage, or epilepsy was not reported.

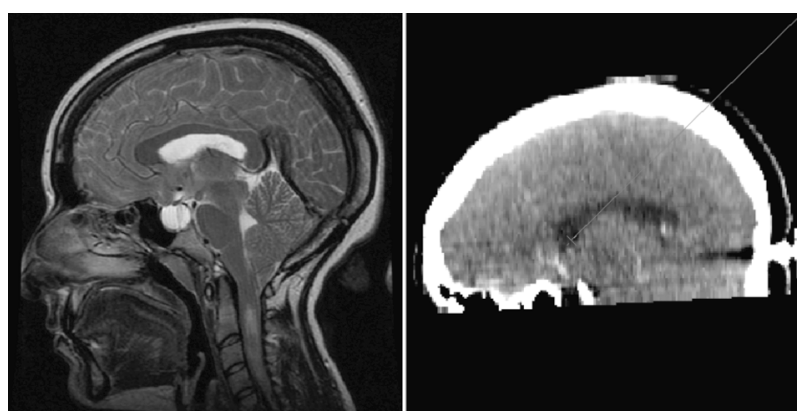

Fig. (2A): Showing case No 6 presented with spontaneous CSF rhinorrhea. Preoperative MRI showed Chiari I malformation with marked tonsillar herniation and empty sella and intraoperative CT showing the trajectory.

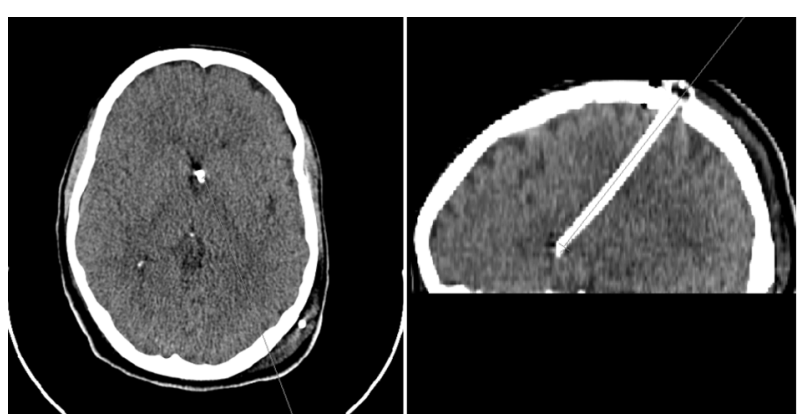

Fig: (2B): Showing post-operative CT scan after VPS insertion.

\section{Discussion}

IIH is a disease of elevated ICP without any cause. It is commonly treated by medical treatment and decreasing the weight. Surgery is done for patients who not improved by medications, developed rapidly progressive symptoms, or presented with fulminant visual loss. Surgical methods of treatment include (ONSF), CSF diversion (i.e., LPS or VPS), venous sinus stenting, and bariatric surgery. Binder et al., recommended CSF diversionary procedures (LPS or VPS) over ONSF as initial surgical treatment for IIH. The advantage of shunting over optic nerve sheath fenestration surgery is that it "treats the underlying problem" of increased intracranial pressure. Management of increased ICP can be done by CSF diversion procedures through LPS or VPS. In general LPS is more commonly performed than VPS due to absence of potential intracranial complications and the difficulty in shunting small ventricles. However, LPS has a higher revision and complication rates $[47,48]$. Complications as obstruction, shunt migration, infection, overdrainage, and tonsillar herniation can occur with LPS. The presence of small or slit-like ventricles may preclude the use of VPS. To overcome this barrier, the use of stereotactic guided VP shunt has been proposed $[49,50]$.

As a result of rapid progress and development in stereotactic surgery, the ventricular shunt insertion for surgical management of IIH becomes another option that can avoid LP shunts problems. The use of both frame-based and frameless stereotaxy has been described, with a lower overall shunt failure rate than described for LP shunts $[38,50-52]$.

In this study, we had sixteen patients with IIH (14 females \& 2 males) with mean age of 29.5 years. These results are similar to the results of most literature concluded that IIH commonly affects overweight women of childbearing age $[28,46]$.

Headache (100\%), papilledema, and visual field defect $(87.5 \%)$ were the most common symptoms and signs among our patients. In most previous studies, headache was the commonest symptom and found in about $60 \%-90 \%$ of patients [7,13-16]. Papilledema, is the hallmark clinical sign of IIH $[1,17]$. About $90 \%$ of patients have visual field deficits at time of presentation $[\mathbf{1 3 , 1 8 , 1 9 ]}$.

In this study, 11 patients (68.8\%) had previous LPS insertion with at least one trial of revision. Cormaco et al., 2001 reported the same result as he had 9 patients of $13(69.2 \%)$ had previous LPS insertion. 
After ventricular shunt insertion, all patients reported improvement or stabilization of their visual symptoms. Headache resolved in fourteen $(87.5 \%)$ patients whereas, two patients had infrequent headache that managed medically. Kandasamy et al., reviewed 18 patients with IIH who underwent stereotactic image-guided VPS. They had the same results at the last follow-up (mean follow-up of 21 months). Eighty-three percent $(83 \%)$ of patients reported resolution of headache [49].

Ventricular cannulation was successful and accurate at first pass for all patients. The difficulty associated with the insertion of a ventricular catheter in slit type ventricles observed with the disease was managed by using stereotactic image guidance that allowed the procedure to be performed safely with great accuracy. Also, a multiplanar reconstruction software, Praezis plus 3 was used in all cases which increase the accuracy. In Woodworth et al., series, they achieved $100 \%$ accuracy of VP shunt insertion using image guidance with only 1 pass of the catheter needed on each patient [27].

We had two patients $(12.5 \%)$ required revision of the VP shunt for distal obstruction. We had no mortality or significant morbidity in this study. No incidences of intracranial hemorrhages, shunt infection, over drainage, or epilepsy were reported.

In Huang et al., study in 2014 that included 19 patients, all of them had VP shunts placed, with an average follow-up of 21 months. During this period, 2 patients required revision. They concluded that image-guided ventricular shunt is the preferred CSF diversion approach at their institution [28].

LPS and VPS can be associated with a number of complications, the commonest being shunt revision. Overdrainage and tonsillar herniation only occurred with lumboperitoneal shunts.

Lumboperitoneal shunts are most commonly used for IIH. Their drawbacks include acquired Chiari malformation due to overdrainage or lowtension headaches, radiculopathy, and a high frequency of shunt malfunction. A retrospective analysis of 27 patients, diagnosed as IIH, treated with LPS, and the mean follow-up period was of 6 years, showed that $56 \%$ of patients required revision. The average revision rate was 2.4 per patient, with a median time to first revision of 11 months. Shunt revisions were done due to shunt failure or low CSF pressure [40].

In Niotakis et al., study published in 2013, all patients had LPS for surgical management of IHH and all patients required revision. Six of them $(85.7 \%)$ had the first revision within 4 months after their first shunt placement [29].

In 2004, Friedman and Jacobson reviewed the published literature on LPS for IIH and noted the revision rate ranged from 38 to 64\% [48]. Many authors concluded that LPS is associated with high revision rate by 2- to 2.5-fold compared to VPS, and a 3 -fold more obstruction rate $[\mathbf{4 9 , 5 2 , 5 3 ]}$.

Analysis of about 30-year experience with CSF diversion procedures for IIH at Johns Hopkins School of Medicine studied 115 shunts (79 LPS and 36 VPS or VAS). Lumboperitoneal shunts required revision $(86 \%)$ than ventricular shunts (44\%). Overdrainage and tonsillar herniation only occurred with lumboperitoneal shunts, which were twice as likely as ventricular shunts to become obstructed. Ventricular shunts placed with imageguided stereotactic technique were all accurately inserted [52]. Abubaker et al, followed 25 patients who underwent either an LPS or a VPS, and found the revision rate for LPS was $60 \%$, compared with only $30 \%$ for VPS [53].

A case series of 21 patients who underwent LPS had a mean revision rate of three per patient during a mean follow-up of 21 months. This case series also found $30 \%$ of patients developed cerebellar tonsillar herniation. The authors of this study concluded that the complication rate of LPS is unacceptably high and an alternative way of CSF diversion should be pursued. This same institution published a case series of 18 patients who subjected to stereotactic image-guided VPS. Only four of these patients $(22.2 \%)$ required shunt revision. No significant morbidity or mortality was reported in this case series. The authors of the study concluded that stereotactic image-guided VPS is a safe and effective surgical option to treat IIH which may offer efficacy equal to that of LPS with fewer complications [49,54].

Lumbar radiculopathy is a frequent complaint following LP shunt placement [38]. Two patients in this study had severe sciatica from radicular compression after insertion of LPS. Eggenberger, et al., reported that five of their 27 patients who underwent LPS placement complained of radicular pain and three of the five required shunt revision for this reason [40].

In this study, we had four patients with abdominal wound dehiscence associated with persistent CSF leak from the wound due to decrease absorptive capacity of the peritoneal cavity after multiple 
revisions of LP shunt. Ventriculoatrial shunt (VA) using intraoperative plain X-ray chest and intraoperative sonography for percutaneous placement of the distal catheter was performed for these patients. This technique was described by Metellus et al., 2009 and they concluded that it is a safe, effective, and reliable technique that is simple to learn [55].

Four patients undergoing medical treatment for IIH presented with spontaneous CSF rhinorrhea were recorded by Clark et al., 1994. They concluded that although CSF rhinorrhea is a rare complication of IIH, CSF diversion can control the ICP and the CSF rhinorrhea. Direct repair of the fistula may be also advised to decrease the risk of meningitis and pneumocephalus [56]. In our study, we reported a patient presented with spontaneous CSF rhinorrhea after cessation of the medical treatment. We preferred stereotactic VP shunt because the preoperative MRI showed marked tonsillar herniation. She clinically improved and the CSF rhinorrhea stopped spontaneously few weeks later. The patient was stable along the follow-up (55 months). Ransom et al., 2006 reported similar results in a case report [57].

Catheterization of very small ventricles associated with IIH is difficult but this difficulty can now be effectively addressed by using suitable neuronavigation systems. The lower failure rates in stereotactically placed ventricular catheter may significantly overcome the potential drawback of increased cost. All the previously published studies on SVPS for IIH concluded that LPS had a revision and shunt failure rate more than stereotactically placed VP shunts $[\mathbf{5 1 , 3 8 , 5 2 , 5 0 ] \text { . }}$

We recognized the limitations of our study. The first is the retrospective design, leading to gaps in data collection. Another limitation is the sample size. Although our sample size is similar to other studies, it is small which limits statistical significance. Most studies on outcomes on CSF shunting to date are retrospective in nature [58].

\section{Conclusion:}

Ventricular shunts had obstruction and revision rate lower than LP shunts. So it is concluded that stereotactic guided ventricular catheter placement is an effective, safe and durable alternative surgical option in a lot of cases with IIH that are refractory to the traditional medical and surgical management. Due to the great advances in image guided surgery, the effectiveness and safety of VP shunts in management of IIH has been markedly increased.

\section{References}

1- CORBETT J.J., SAVINO P.J., THOMPSON H.S., et al: Visual loss in pseudotumor cerebri. Follow-up of 57 patients from five to 41 years and a profile of 14 patients with permanent severe visual loss. Arch. Neurol., 39: 461-474, 1982.

2- WALL M. and GEORGE D.: Idiopathic intracranial hypertension. A prospective study of 50 patients. Brain, 114: 155-180, 1991.

3- FRIEDMAN D.I. and JACOBSON D.M.: Diagnostic criteria for idiopathic intracranial hypertension. Neurology, 59: 1492-95, 2002.

4- DURCAN F.J., CORBETT J.J. and WALL M.: The incidence of pseudotumor cerebri. Population studies in Iowa and Louisiana. Arch. Neurol., 45: 875-7, 1988.

5- JOHNSTON I., PATERSON A. and BESSER M.: The treatment of benign intracranial hypertension: A review of 134 cases. Surg. Neurol., 16: 218-24, 1981.

6- RADHAKRISHNAN K., AHLSKOG J.E., CROSS S.A., et al.: Idiopathic intracranial hypertension (pseudotumor cerebri). Descriptive epidemiology in Rochester, Minn, 1976 to 1990. Arch. Neurol., 50: 78-80, 1993.

7- BABIKIAN P., CORBETT J. and BELL W.: Idiopathic intracranial hypertension in children: the Iowa experience. J. Child Neurol., 9: 144-9, 1994.

8- BRUCE B.B., KEDAR S., VAN STAVERN G.P., et al: Idiopathic intracranial hypertension in men. Neurology, 72: 304-309, 2009.

9- DIGRE K.B. and CORBETT J.J.: Pseudotumor cerebri in men. Arch. Neurol., 45: 866-72, 1988.

10- BRUCE B.B., KEDAR S., VAN STAVERN G.P., et al.: Atypical idiopathic intracranial hypertension: normal BMI and older patients. Neurology, 74: 1827-32, 2010.

11- IRELAND B., CORBETT J.J. and WALLACE R.B.: The search for causes of idiopathic intracranial hypertension. A preliminary case-control study. Arch. Neurol., 47: 315$20,1990$.

12- WALL M.: Idiopathic intracranial hypertension. Neurol. Clin., 28: 593-617, 2010.

13- SPENNATO P., RUGGIERO C., PARLATO R.S., et al.: Pseudotumor cerebri. Childs. Nerv. Syst., 27: 215-35, 2011.

14- PHILLIPS P.H.: Pediatric pseudotumor cerebri. Int. Ophthalmol. Clin., 3: 51-9, 2012.

15- FRIEDMAN D.I.: Idiopathic intracranial hypertension. Curr. Pain. Headache. Rep., 11: 62-8, 2007.

16- ELDES N.H. and YILMAZ Y.: Pseudotumor cerebri in children: Etiological, clinical features, and treatment modalities. Eur. J. Paediatr. Neurol., 16: 349-55, 2012.

17- WALL M. and GEORGE D.: Idiopathic intracranial hypertension. A prospective study of 50 patients. Brain, 114: 155-80, 1991.

18- RANGWALA L.M. and LIU G.T.: Pediatric idiopathic intracranial hypertension. Surv. Ophthalmol., 52: 597617, 2007. 
19- CINCIRIPINI G.S., DONAHUE S. and BORCHERT M.S.: Idiopathic intracranial hypertension in prepubertal pediatric patients: Characteristics, treatment, and outcome. Am. J. Ophthalmol., 127: 178-82, 1999.

20- GUCER G. and VIERNSTEIN L.: Long-term intracranial pressure recording in the management of pseudotumor cerebri. J. Neurosurg., 49: 256-63, 1978.

21- JOHNSON L.N., KROHEL B.G., MADSEN R.W., et al: The role of weight loss and acetazolamide in the treatment of idiopathic intracranial hypertension. Ophthalmology, 105: 1313-17, 1998.

22- WANDSTRAT T.L. and PHILLIPS J.: Pseudotumor cerebri responsive to acetazolamide. Ann. Pharmacother., 29: 318, 1995.

23- ROWE F.J. and SARKIES N.J.: The relationship between obesity and idiopathic intracranial hypertension. Int. J. Obes. Relat. Metab. Disord, 23: 54-9, 1999.

24- AMARAL J.F., TSIARIS W., MORGAN T., et al.: Reversal of benign intracranial hypertension by surgically induced weight loss. Arch. Surg., 122: 946-9, 1987.

25- KUPERSMITH M.J., GAMELL L., TURBIN R., et al: Effects of weight loss on the course of idiopathic intracranial hypertension in women. Neurology, 50: 1094-8, 1998.

26- SUGERMAN H.J., FELTON W.L. III, SALVANT J.B. Jr., et al.: Effects of surgically induced weight loss on idiopathic intracranial hypertension in morbid obesity. Neurology, 45: 1655-9, 1995.

27- WOODWORTH G.F., MCGIRT M.J., ELFERT P., et al.: Frameless stereotactic ventricular shunt placement for idiopathic intracranial hypertension. Stereotact. Funct Neurosurg, 83: 12-16, 2005.

28- HUANG L.C., WINTER T.W., HERRO A.M., et al.: Ventriculoperitoneal shunt as a treatment of visual loss in idiopathic intracranial hypertension. J. Neuroophthalmol., 34: 223-8, 2014.

29- NIOTAKIS G., GRIGORATOS D., CHANDLER C., et al.: CSF diversion in refractory idiopathic intracranial hypertension: Single-centre experience and review of efficacy. Childs Nerv. Syst., 29: 263-7, 2013.

30- BROURMAN N.D., SPOOR T.C. and RAMOCKI J.M.: Optic nerve sheath decompression for pseudotumor cerebri. Arch. Ophthalmol., 106: 1378-83, 1988.

31- CORBETT J.J., NERAD J.A., TSE D.T., et al.: Results of optic nerve sheath fenestration for pseudotumor cerebri. The lateral orbitotomy approach. Arch. Ophthalmol., 106: 1391-7, 1988.

32- GOH K.Y., SCHATZ N.J. and GLASER J.S.: Optic nerve sheath fenestration for pseudotumor cerebri. J. Neuroophthalmol., 17: 86-91, 1997.

33- KELMAN S.E., HEAPS R., WOLF A., et al.: Optic nerve decompression surgery improves visual function in patients with pseudotumor cerebri. Neurosurgery, 30: 391-5, 1992.

34- BRODSKY M.C. and RETTELE G.A.: Protracted postsurgical blindness with visual recovery following optic nerve sheath fenestration. Arch. Ophthalmol., 115: 14734, 1997.
35- FLYNN W.J., WESTFALL C.T. and WEISMAN J.S.: Transient blindness after optic nerve sheath fenestration. Am. J. Ophthalmol., 117: 678-9, 1994.

36- PLOTNIK J.L. and KOSMORSKY G.S.: Operative complications of optic nerve sheath decompression. Ophthalmology, 100: 683-90, 1993.

37- SMITH K.H., WILKINSON J.T. and BRINDLEY G.O.: Combined third and sixth nerve paresis following optic nerve sheath fenestration. J. Clin. Neuro. Opthalmol., 12: 85-7, 1992.

38- CORMACO O., JAMES A. and FREDRIC B.: Refractory idiopathic intracranial hypertension treated with stereotactically planned ventriculoperitoneal shunt placement. Neurosurg. Focus, 10: 1-4, 2001.

39- CHUMAS P.D., KULKARNI A.V., DRAKE J.M., et al.: Lumboperitoneal shunting: A retrospective study in the pediatric population. Neurosurgery, 32: 376-83, 1993.

40- EGGENBERGER E.R., MILLER N.R. and VITALE S.: Lumboperitoneal shunt for the treatment of pseudotumor cerebri. Neurology, 46: 1524-30, 1996.

41- JOHNSTON I., BESSER M. and MORGAN M.K.: Cerebrospinal fluid diversion in the treatment of benign intracranial hypertension. J. Neurosurg., 69: 195-202, 1988.

42- ROSENBERG M.L., CORBETT J.J., SMITH C., et al.: Cerebrospinal fluid diversion procedures in pseudotumor cerebri. Neurology, 43: 1071-2, 1993.

43- McCALLUM J.: Combined frameless stereotaxy and neuroendoscopy in placement of intracranial shunt catheters. Pediatr. Neurosurg., 26: 127-9, 1997.

44- PANG D. and GRABB P.A.: Accurate placement of coronal ventricular catheter using stereotactic coordinate-guided free-hand passage. Technical note. J. Neurosurg., 80: 750$5,1994$.

45- NIOTAKIS G., GRIGORATOS D., CHANDLER C., et al.: CSF diversion in refractory idiopathic intracranial hypertension: Single-center experience and review of efficacy. Childs. Nerv. Syst., 29: 263-7, 2013.

46- KO M.W.: Idiopathic intracranial hypertension. Current Treatment Options in Neurology, 13: 101-8, 2011.

47- BINDER D.K., HORTON J.C., LAWTON M.T., et al.: Idiopathic intracranial hypertension. Neurosurgery, 54: 538-51, 2004.

48- FRIEDMAN D.I. and JACOBSON D.M.: Idiopathic intracranial hypertension. J. Neuroophthalmol., 24: 13845, 2004.

49- KANDASAMY J., HAYHURST C., CLARK S., et al.: Electromagnetic stereotactic ventriculoperitoneal CSF shunting for idiopathic intracranial hypertension: A successful step forward? World Neurosurg., 75: 155-60, 2011.

50- TARNARIS A., TOMA A.K., WATKINS L.D. and KITCHEN N.D.: Is there a difference in outcomes of patients with idiopathic intracranial hypertension with the choice of cerebrospinal fluid diversion site? A single center experience. Clin. Neurol. Neurosurg., 113: 477-9, 2011.

51- TULIPAN N., LAVIN P.J. and COPELAND M.: Stereotactic ventriculoperitoneal shunt for idiopathic intracranial hypertension: technical note. Neurosurgery, 43: 175-7, 1998. 
52- MCGIRT M.J., WOODWORTH G., THOMAS G., MILLER N., WILLIAMS M. and RIGAMONTI D.: Cerebrospinal fluid shunt placement for pseudotumor cerebriassociated intractable headache: Predictors of treatment response and an analysis of long-term outcomes. J. Neurosurg., 101: 627-32, 2004.

53- ABUBAKER K., ALI Z., RAZA K., BOLGER C., et al: Idiopathic intracranial hypertension: Lumboperitoneal shunts versus ventriculoperitoneal shunts-case series and literature review. Br. J. Neurosurg., 25: 94-9, 2011.

54- KARABATSOU K., QYIGLEY G., BUXTON N., et al: Lumboperitoneal shunts: Are the complications acceptable? Acta Neurochir (Wien), 146: 1193-7, 2004.

55- METELLUS P., HSU W., KHARKAR S., et al.: Accuracy of percutaneous placement of a ventriculoatrial shunt under ultrasonography guidance: A retrospective study at a single institution. J. Neurosurg., 110: 867-70, 2009.

56- CLARK D., BULLOCK P., HUI T. and FIRTH J: Benign intracranial hypertension: A cause of CSF rhinorrhoea. J. Neurol. Neurosurg. Psychiatry, 57: 847- 9, 1994.

57- RANSOM E.R., KOMOTAR R.J., MOCCO J., et al.: Shunt failure in idiopathic intracranial hypertension presenting with spontaneous cerebrospinal fluid leak. J. Clin. Neurosci., 13: 598-602, 2006.

58- CRISTINA VICTORIO and DAVID ROTHNER: Diagnosis and Treatment of Idiopathic Intracranial Hypertension (IIH) in Children and Adolescents. Curr. Neurol. Neurosci. Rep., 13: 336, 2013.

\section{إستخدام جراحة الأنحياز المجسم فى وضع قسطرة الصمام داخل بطينات الهخ

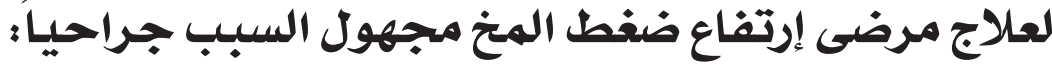 الفاعلية والأمان}

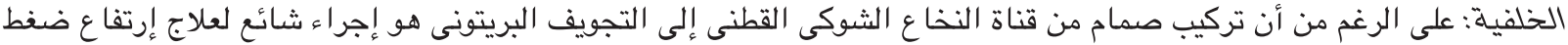

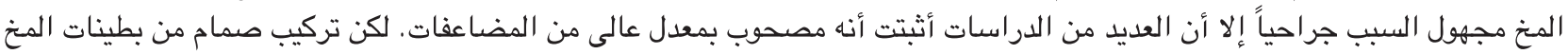
إلى التجويف البريتونى إجراء غير شائع وذلك بسبب صغر حجم بطينات المخ فى مرضى إرتفاع ضغط المخ مجهول السبب مما يزيد من صعوبة السية الجراحة.

الهدف من الدراسة: تقييم مدى دقة وأمان إستخدام جراحة الأنحياز الهجسم فى وضع قسطرة الصمام داخل بطينات المخ لعلاج مرضى إرتفاع ضغط المخ مجهول السبب جراحياً.

المرضى والطرق: تمت مراجعة الملفات الطبية لكل المرضى الذين أجريت لهم جراحات الأنحياز المجسم لوضع قسطرة الصمام داخل

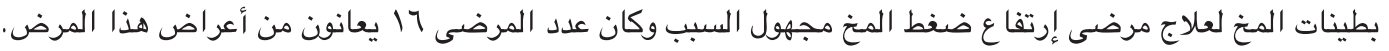

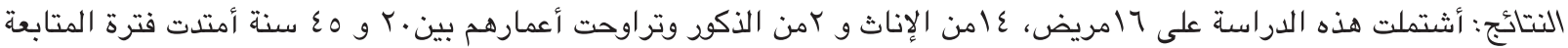

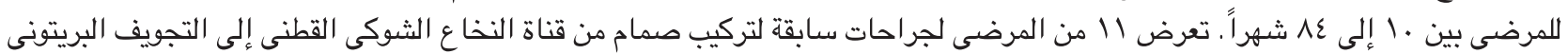

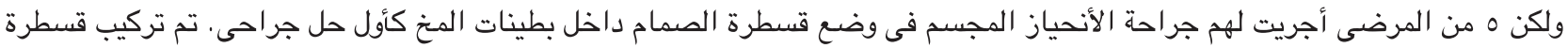

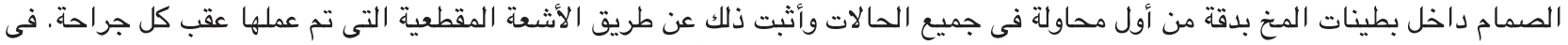

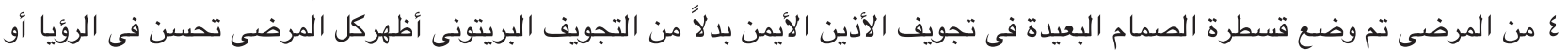

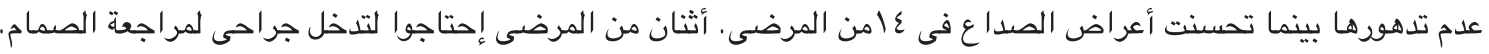
الإستتاج: تعتبر جراحة الأنحياز المجسم فى وضع قسطرة الصمام داخل بطينات المخ لعلاج مرضى إرتفاع ضفط المخ مجهول السبب طريقة فعالة وآمنة بالإضافة إلى الطرق التقليدية والتى قد تفشل فى بعض الإن الأحيان.
} 